\title{
Mobility and maternal position during childbirth in Tanzania: an exploratory study at four government hospitals Helen Lugina ${ }^{1}$, Rose Mlay ${ }^{1}$ and Helen Smith*2
}

\author{
Address: ${ }^{1}$ Africa Midwives Research Network and School of Nursing, Muhimbili University College of Health Sciences, University of Dar es Salaam, \\ PO Box 65004, Tanzania and ${ }^{2}$ Effective Health Care Alliance Programme, International Health Research Group, Liverpool School of Tropical \\ Medicine, Liverpool, L3 5QA, UK \\ Email: Helen Lugina - hlugina@muchs.ac.tz; Rose Mlay - rmlay@muchs.ac.tz; Helen Smith* - cjdhel@liv.ac.uk \\ * Corresponding author
}

Published: 19 February 2004

BMC Pregnancy and Childbirth 2004, 4:3
Received: 15 October 2003

Accepted: 19 February 2004

This article is available from: http://www.biomedcentral.com/I47/-2393/4/3

(C) 2004 Lugina et al; licensee BioMed Central Ltd. This is an Open Access article: verbatim copying and redistribution of this article are permitted in all media for any purpose, provided this notice is preserved along with the article's original URL.

\begin{abstract}
Background: Emerging research evidence suggests a potential benefit in being upright in the first stage of labour and a systematic review of trials suggests both benefits and harmful effects associated with being upright in the second stage of labour. Implementing evidence-based obstetric care in African countries with scarce resources is particularly challenging, and requires an understanding of the cumulative nature of science and commitment to applying the most up to date evidence to clinical decisions. In this study, we documented current practice rates, explored the barriers and opportunities to implementing these procedures from the provider perspective, and documented women's preferences and satisfaction with care.
\end{abstract}

Methods: This was an exploratory study using quantitative and qualitative methods. Practice rates were determined by exit interviews with a consecutive sample of postnatal women. Provider views were explored using semi-structured interviews (with doctors and traditional birth attendants) and focus group discussions (with midwives). The study was conducted at four government hospitals, two in Dar es Salaam and two in the neighbouring Coast region, Tanzania.

Main outcome measures: Practice rates for mobility during labour and delivery position; women's experiences, preferences and views about the care provided; and provider views of current practice and barriers and opportunities to evidence-based obstetric practice.

Results: Across all study sites more women were mobile at home (I5.0\%) than in the labour ward (2.9\%), but movement was quite restricted at home before women were admitted to labour ward ( $51.6 \%$ chose to rest with little movement). Supine position for delivery was used routinely at all four hospitals; this was consistent with women's preferred choice of position, although very few women are aware of other positions. Qualitative findings suggest obstetricians and midwives favoured confining to bed during the first stage of labour, and supine position for delivery.

Conclusions: The barriers to change appear to be complicated and require providers to want to change, and women to be informed of alternative positions during the first stage of labour and delivery. We believe that highlighting the gap between actual practice and current evidence provides a platform for dialogue with providers to evaluate the threats and opportunities for changing practice. 


\section{Background}

In Tanzania $98 \%$ of pregnant women receive antenatal care, but only $44 \%$ deliver at a health facility [1]. This varies by location; in urban Dar Es Salaam $86 \%$ of deliveries take place at a health facility, while only $51 \%$ of deliveries in the Coastal region (a rural area) are at a health facility [1]. Many health professionals working in maternity care at these facilities are unaware of the most up-to-date and accurate information that might improve outcomes and women's experience of childbirth [2]. Women who choose to deliver in government hospitals therefore risk being subjected to outdated practices, some of which may be harmful. Due to staff shortages and lack of resources, few midwives are able to attend regional or national training to update their skills and knowledge. The Africa Midwives Research Network (AMRN), a collaboration of midwives from more than 10 African countries, has improved midwives' access to current information on good practice by providing regional and in-country evidence-based practice workshops [3]. The Network believes that evidence-based practice should be given priority so that health care providers in Tanzania are aware of what works best for antenatal, intrapartum, postpartum and infant care.

Over the last two decades, health care has experienced a paradigm shift in thinking away from traditional belief and opinion-based practice, towards clinical decisions that are based on the best available evidence [4]. Evidence-based practice is no longer a metaphor for what ought to be done; it is now the only accepted mode of practice. Packages such as the WHO Reproductive Health Library (RHL) [5] and the Better Births Initiative [6] are helping health professionals to use the information from systematic reviews in practice. But changing established practice is a slow and incremental process that requires an understanding of the cumulative nature of science, and commitment to applying the most up to date evidence to clinical decisions [7].

Obstetric care has a history of unchecked practice $[8,9]$, which is one reason why interventions with little or no benefit continue to be used, and those with potential for improving outcomes and experiences are slow to be adopted. For example, evidence from systematic reviews produced within the Cochrane Collaboration demonstrate the benefit of steroids in pre-term delivery [10], and the benefit of magnesium sulphate for eclampsia [11], yet clinicians have been slow to change their practice, favouring traditional approaches to these life-threatening conditions $[12,13]$.

Members of the AMRN identified two obstetric procedures where current practice can improve, and consequently have a direct impact on, the quality of care women receive. Emerging research evidence suggests a potential benefit in being upright in the first stage of labour [14] and a systematic review of trials suggests both benefits and harmful effects associated with being upright in the second stage of labour [15]. Given the equivocal evidence, and until methodologically stringent trial data are available, women should be allowed to make informed choices about their position during labour and for delivery. Current recommendations from the Royal College of Obstetricians and Gynaecologists in the UK state that midwives should encourage women to choose whatever position is most comfortable in labour and delivery [16].

In this study we documented the use of positions during labour and delivery in government hospitals in Tanzania. We explored women's experience during labour and delivery, their satisfaction with care and their preferred position during first stage of labour and delivery using exit interviews, and obtained provider views about these practices through focus group discussions and in-depth interviews. The methods employed are similar to those used in studies conducted in China [17], South Africa [6], and Egypt [18] to compare practice to evidence based information, and explore women and provider views of the care they receive and provide.

\section{Methods \\ Study sites}

The study was conducted at four hospitals, two in Dar es Salaam and two in the neighbouring Coast region. The hospitals were purposefuly selected as they represented different levels of care and would therefore allow us to explore variations in practice: the national referral hospital receives cases from Dar Es Salaam and other regions in Tanzania; the regional and district hospitals provide secondary level services in Dar Es Salaam and the Coast region. The referral and district hospitals are situated in urban Dar Es Salaam, the regional hospital is located in a peri-urban area 30 kilometres from the city, and the Coastal district hospital is in a rural area. Table 1 shows characteristics of the study sites; columns three and four indicate the number of doctors and midwives working in the maternity ward at each hospital.

\section{Data collection}

We used structured exit interviews with postnatal women at each hospital ( $\mathrm{n}=1151$ in total) to document sociodemographic characteristics, the use of mobility during labour, the position for delivery, and women's views about these practices. Women's postpartum opinion is considered to be the most appropriate method for recording mobility and delivery position in this setting. These practices are not commonly documented in maternity registers or women's notes and therefore a review of clinical 
Table I: Study site characteristics

\begin{tabular}{lllll}
\hline Type & Location & Doctor/AMO/CO* & Midwives & Deliveries/month \\
\hline Referral & Urban, Dar Es Salaam & 20 & 25 & 1,200 \\
District & Urban, Dar Es Salaam & 18 & 4 & 1,000 \\
Regional & Peri-urban, Coast region & 13 & 17 & 500 \\
Coastal district & Rural, Coast region & 4 & 10 & 250 \\
\hline
\end{tabular}

$* \mathrm{AMO}=$ Assistant Medical Officer; $\mathrm{C} / \mathrm{O}=$ Clinical Officer

Table 2: Sample size for each data collection method

\begin{tabular}{lllll}
\hline Hospital & Exit interview (women) & Focus group discussion (midwives) & In-depth interview (doctors) & In-depth interview (TBA's) \\
\hline Referral & 419 & 1 & 1 & Not done $^{+}$ \\
District & 333 & 1 & $I^{*}$ & 1 \\
Regional & 250 & $I^{*}$ & 2 & 1 \\
Coastal district & 149 & 1 & 1 & 1 \\
\hline
\end{tabular}

+ TBA practice is not common in this urban setting. * Data in the form of written notes only, due to poor quality tape recording.

records was not possible. Direct observation is an alternative method, but can result in significant observer and provider bias. Trained midwives, not working in labour wards at the study hospitals, conducted exit interviews consecutively with healthy women with no complications who had delivered by spontaneous vaginal delivery prior to discharge between March and July 2001 at all four sites. Women with complications and those who delivered by Caesarean section were excluded because these indications might have prevented them from being mobile or delivering in a position other than supine, even if desired by the woman. Interviews were conducted in Kiswahili and women gave verbal informed consent. We calculated the sample size using StatsDirect software package [19] based on the number of deliveries at each site and the estimated prevalence of mobility and position other than supine; we allowed for a deviation of $2.5 \%$ from the true population rate. Table 2 shows the number of women interviewed at each hospital.

We explored midwives' views about the feasibility of allowing women to be mobile during labour, their attitudes, skills and confidence in using positions other than supine, and what should be done to promote the use of these practices using focus group discussions at each study site ( $\mathrm{n}=4$ focus group discussions). A researcher from the School of Nursing, Muhimbili University College of Health Sciences (MUCHS), conducted all focus group discussions in Kiswahili. Groups comprised approximately 12 midwives available and willing to participate on the day; facilitators followed a pre-specified topic guide, and the discussions were tape-recorded with participants' consent.

We used semi-structured interviews with a convenience sample of doctors to explore their views about the benefits and problems associated with mobility during labour and positions other than supine for delivery, and what should be done to promote the use of these practices in their hospitals ( $\mathrm{n}=5$ interviews). We also used semi-structured interviews to obtain traditional birth attendants' (TBAs) experiences of delivering women in positions other than supine, and their views about mobility during labour. TBAs were identified and invited for interview in collaboration with District Maternal and Child Health Co-ordinators and District Nursing Officers; interviews were conducted at the study sites. Researchers from MUCHS conducted all interviews with doctors and TBAs in Kiswahili. Interviews typically lasted one hour, and were taperecorded with participants' permission.

\section{Data analysis}

A statistician from MUCHS entered and cleaned data to check for inconsistencies; HL, RM and HS analysed data from exit interviews using Epi-Info [20]. We used frequencies, means and ranges to describe the data and basic cross tabulations to explore variation in practice across the four study sites.

Tape recordings and written notes from focus group discussions and in-depth interviews (in Kiswahili) were analysed using principles of the Framework approach [21]. Frequently used in applied qualitative research, the 
Table 3: Characteristics of women by study site

\begin{tabular}{|c|c|c|c|c|c|}
\hline Characteristics & Referral & District & Regional & Coastal district & Total \\
\hline $\mathrm{N}$ (sample size)* & 419 & 333 & 250 & 149 & $|15|$ \\
\hline Mean age $( \pm S D)$ & $25.4( \pm 5.7)$ & $25.1( \pm 4.7)$ & $23.9( \pm 5.8)$ & $23.7( \pm 5.6)$ & $24.8( \pm 5.4)$ \\
\hline Age range & $(14-40)$ & $(16-40)$ & (I5-45) & $(15-40)$ & $(14-45)$ \\
\hline First delivery (\%) & $186(44.4)$ & $128(38.4)$ & $116(46.4)$ & $61(40.9)$ & 491 (42.7) \\
\hline Attended ANC (\%) & $4 \mid 4(99.8)$ & $333(100)$ & $246(99.6)$ & $149(100)$ & I I 42 (99.8) \\
\hline
\end{tabular}

* Sample size differs from original $\mathrm{N}$ for some variables due to missing data/non-responses. Source: Exit interviews

Framework approach is a systematic process that is heavily based on participant's original accounts and observations, but is sometimes described as a more deductive process because analysis begins with a priori issues or previously defined study objectives. The key stages of analysis are similar to traditional methods of familiarisation, identifying a thematic framework, coding, and interpretation; each time the thematic framework is applied to transcripts the themes and categories become more responsive to issues emerging from the data (as in grounded theory) [22]. HL and RM independently identified themes (using an a priori topic guide and key issues emerging from the data) and coded transcripts using open coding methods [23]. Identified themes were transcribed and translated into English for further coding and interpretation. Consensus was reached on common themes and outlying responses by discussion among HL, RM and HS. Back translation to Kiswahili was not done due to resource limitations.

\section{Ethical approval}

Ethical approval was obtained from the Muhimbili University College of Health Sciences Research and Publications Committee; this is a rigorous process and ethical clearance from the Tanzanian institute was deemed sufficient since the research question was generated, and the research conducted and managed, in Tanzania. Permission to collect data and conduct the study was secured from the relevant person in charge at each hospital. Participation in exit interviews, focus group discussions and indepth interviews was voluntary and respondent confidentiality was observed throughout the study.

\section{Results}

Table 3 shows the characteristics of women interviewed at each study site. The mean age and age range of women were similar across the hospitals. On average, $43 \%$ of women were primiparas, and almost all had attended antenatal care prior to delivering in hospital.

\section{Current practice}

Table 4 shows that mobility during labour is not widely practised in the study hospitals. More women were mobile at home after the labour pains started than in the labour ward at each hospital. The greatest difference between mobility at home and in the labour ward was at the district hospital (27.6\% compared to 4.5\%). However, a surprising finding was the apparent restriction on movement prior to admission to the labour ward; across all hospitals, most women chose to rest with little movement when at home $(51.6 \%)$, and just $15 \%$ said they were mobile at home. Another important finding is that $28.3 \%$ of all women who laboured in bed in the labour ward said they wanted to be mobile.

Table 5 shows that supine position (most commonly left lateral position with back slightly to one side) is used routinely at all the study hospitals. Upright positions, including sitting upright and squatting, are used very infrequently. The data suggest that women's preference for delivery position was supine; more than $80 \%$ of women at all hospitals said they would choose supine position. Only very few women at the referral $(1.7 \%)$ and regional $(4.4 \%)$ hospitals said they would choose to deliver in a sitting position. Similarly, squatting would be the choice of very few women at the district, referral, and regional hospitals.

\section{Provider views}

Key themes that emerged from the qualitative data analysis included: the perceived benefits and problems with allowing women to be mobile and deliver in positions other than supine; safety issues; and provider feelings about the skills and confidence required to implement these procedures. Each theme is explored in detail below.

\section{Mobility during labour}

Views expressed by midwives and doctors about mobility during labour were generally positive. During focus group discussions, midwives acknowledged the benefits of mobility; the following extracts highlight typical comments: 
Table 4: Mobility during labour by study site

\begin{tabular}{|c|c|c|c|c|c|}
\hline Variables & Referral & District & Regional & Coastal district & Total \\
\hline$N^{*}$ & 419 & 333 & 250 & 149 & $|15|$ \\
\hline \multicolumn{6}{|l|}{ At home: } \\
\hline Mobile (\%) & $46(11.3)$ & $89(27.6)$ & $32(12.9)$ & $2(1.4)$ & $169(15.0)$ \\
\hline Stayed in bed (\%) & $162(39.9)$ & $81(25.1)$ & 84 (33.7) & $44(29.9)$ & $371(33.0)$ \\
\hline Rested, little movement (\%) & $195(48.0)$ & $151(48.2)$ & $132(53.0)$ & $101(68.7)$ & $581(51.6)$ \\
\hline \multicolumn{6}{|l|}{ In labour ward: } \\
\hline Mobile (\%) & $13(3.1)$ & $14(4.5)$ & $5(2.0)$ & $0(0)$ & $32(2.9)$ \\
\hline Stayed in bed (\%) & $28 I(67.5)$ & $148(47.3)$ & $161(64.7)$ & $81(56.3)$ & $671(59.8)$ \\
\hline Rested, little movement (\%) & $120(28.8)$ & $151(48.2)$ & $83(33.3)$ & $63(43.8)$ & $417(37.2)$ \\
\hline Wanted to be mobile (\%)! & $76(27.2)$ & $56(37.8)$ & $40(24.8)$ & $\mid 7(2 \mid .3)$ & $189(28.3)$ \\
\hline
\end{tabular}

* Sample size differs from original $\mathrm{N}$ for some variables due to missing data/non-responses ' Calculated using those who stayed in bed in the labour ward as the denominator. Source: Exit interviews

Table 5: Position for delivery by study site

\begin{tabular}{|c|c|c|c|c|c|}
\hline Variables & Referral & District & Regional & Coastal district & Total \\
\hline $\mathrm{N}^{*}$ & 419 & 333 & 250 & 149 & $\mid 151$ \\
\hline Supine position (\%) & $398(95)$ & $331(99.4)$ & $250(100)$ & $149(100)$ & I I $28(98.0)$ \\
\hline Sitting upright (\%) & $2(0.5)$ & $(0)$ & $0(0)$ & $0(0)$ & $2(0.2)$ \\
\hline Squatting (\%) & $0(0)$ & $\mathrm{I}(0.3)$ & $0(0)$ & (0) & $\mathrm{I}(0.1)$ \\
\hline Would choose supine position (\%) & $336(80.6)$ & $303(91.0)$ & $209(83.6)$ & $147(100)$ & $995(86.7)$ \\
\hline Would choose sitting upright (\%) & $7(1.7)$ & $0(0)$ & $11(4.4)$ & $0(0)$ & $18(1.6)$ \\
\hline Would choose squatting (\%) & $3(0.7)$ & $2(0.6)$ & $\mathrm{I}(0.4)$ & $0(0)$ & $6(0.5)$ \\
\hline
\end{tabular}

* Sample size differs from original $\mathrm{N}$ for some variables due to missing data/non-responses. Source: Exit interviews

"It is important and beneficial if the mother moves around during the first stage of labour. This will enhance labour contractions as well as foetal descent." (Midwife, Focus Group Discussion (FGD), referral hospital)

"For me I think mobility during the first stage of labour is important because it helps in descent and it enhances the progress of labour." (Midwife, FGD, coastal district hospital)

During in-depth interviews, doctors also commented on the benefits of mobility in hastening labour and speeding descent:

"Encouraging mobility during labour is good practice because it makes the contractions stronger. If contractions are stronger, the duration of labour will be shorter and there will be fewer interventions, which may be costly and may consume time while the maternal and foetal outcomes are being compromised." (Doctor, interview, district hospital)
"Being mobile helps because when you compare a woman who just stays in bed and that one who moves around, the speed of the engagement of the head will differ although some may say the process of labour takes a natural course. But things like movement and emptying the bladder frequently help in the progress of labour." (Doctor, interview, regional hospital)

One doctor mentioned that mobility reduces pain and anxiety in women during labour:

"Moving around helps the mother psychologically. If a woman stays in bed or in one place, she may feel more pain, but if she walks or moves, this helps in decreasing anxiety and reducing the labour pain." (Doctor, interview, regional hospital).

Both midwives and doctors emphasised that a woman's condition dictated whether or not she could be mobile during labour. They expressed concern that a thorough assessment should take place before a woman is allowed to move around, and those in active or second stage of labour should not be mobile: 
"Being mobile or walking around is $\mathrm{OK}$, but it depends on the stage of labour. If a woman is in the first stage of labour and membranes are intact, the woman can be allowed to walk around." (Midwife, FGD, coastal district)

" Walking around is good but with proper assessment and monitoring. If there is no problem with the labour, the woman should be allowed to walk." (Doctor, interview, district hospital)

Provider views about the barriers to allowing women to be mobile during labour typically centred on safety issues and the labour ward environment. A common concern among midwives was that they cannot observe women if they are outside the labour ward; one midwife explained:

"I would feel safe if she walks within the labour ward, not outside. If she goes outside we will lose control. We can not observe her when she is outside." (Midwife, FGD, district hospital)

Other providers feared that they could be blamed for causing danger to the woman and the baby if something happens to the woman outside of the labour ward; a typical comment was:

"Sometimes you may have assessed a woman and found that she is $4 \mathrm{~cm}$ dilated. Labour can go fast and if you allow her to walk she may deliver in the toilet or corridor. The midwife will be responsible for the problem." (Midwife, FGD, referral hospital)

Both midwives and doctors mentioned the labour ward environment as a specific barrier to allowing women to be mobile, and they commented on the overcrowding of labour wards, which precludes women from walking around, as one midwife explained:

"It is difficult to encourage women to be mobile because there is overcrowding, too many patients. In the room for women with normal labour there are sometimes 20 patients to one midwife." (Midwife, FGD, Referral)

A doctor even likened the situation in labour ward to that of being in jail:

"To say the truth when women come to our labour ward it is like being in jail. There is no secret about it. Probably the factors that contribute to this - I am not so sure, but if you take a look at the room for normal labour, there are eight beds but there is no space between the beds. I have tried several times to get women out of bed but it is just impossible. The room is overcrowded, completely overcrowded." (Doctor, interview, referral hospital)
In comparison with hospital delivery environment, TBAs delivering women at home or in the community usually encourage their clients to walk around during labour. One TBA explained her normal practice during interview:

"If women are in the initial stage of labour, I ask them if they want to walk, if they say yes, I tell the women to walk but I walk with them, I walked myself while in labour." (TBA, interview, district hospital)

\section{Position for delivery}

Qualitative findings revealed provider views about the position adopted for delivery. Both midwives and doctors at all study sites agreed that supine position was used routinely, or was the most common position used:

"At our place it is not usual to deliver women in other positions. It is mainly supine position that we use." (Midwife, FGD, district hospital)

"Supine is the most common delivery position used in our hospitals. We are used to this position. That is the position we were taught and even most of the pictures that are found in midwifery and obstetric books are showing women on their backs with knees flexed as they deliver their babies." (Doctor, interview, regional hospital)

A few midwives mentioned that women are sometimes supported in a more upright position using a pillow, or they are told to flex and hold their legs, but this is not usual practice:

"If a woman insists that she wants to deliver in an upright position and she gives me a genuine reason such as difficulties in breathing or high blood pressure, I can provide her with extra pillows to keep her upright and deliver her in that position, although I am not used to it and personally do not prefer it." (Midwife, FDG, regional hospital)

"I can allow a woman to deliver in upright or lateral position if she is calm. In fact I will be more comfortable to deliver the woman in a lateral position by standing or kneeling behind her and supporting the baby as he comes out." (Midwife, FGD, referral hospital)

In addition, both midwives and doctors were of the opinion that supine position is the most convenient, since it enables the attendant to see clearly what is happening during delivery; a typical comment was:

"Delivering a woman in supine is convenient because the provider can control all activities easily and she or he has good view of the whole process of birth and can easily per- 
form procedures, for example, episiotomy." (Midwife, FGD, coastal district hospital)

A midwife at the district hospital, and one doctor at the coastal district hospital suggested that supine position facilitates communication between the attendant and the woman:

"Supine position allows the provider to see the woman's facial expression. In other positions it might not be easy to observe this and the health care provider may miss non-verbal expressions that can aid in understanding the condition of the mother and how she is responding to the labour process." (Midwife, FGD, district hospital)

"In supine position, the provider and the woman are face to face. You see what you are doing and the mother sees you. You can communicate easily with the mother." (Doctor, interview, coastal district hospital)

Providers proposed various barriers to using upright positions such as sitting, squatting or standing; most comments centred on safety of the woman and provider and lack of experience using positions other than supine. For example, one midwife commented that:

"Sometimes upright position can bring more problems. Because if the woman is in that position (upright) and at that very moment she experiences eclampsia! Now I do not know what you (the care provider) will do? Two things are happening at the same time. Will you help the mother or the baby?" (Midwife, FGD, district coastal hospital)

Doctors also expressed concern about the safety of other positions, one suggested:

"Upright is natural, considering the facts about force of gravity and even how the birth canal is made. It is expected that if a woman delivers in upright position the process will take shorter than in supine position. But upright might not be safe. In the upright position, the mother may drop the baby on the floor, leading to problems." (Doctor, interview, referral hospital)

Regarding provider experience with other positions, most commented that they had been taught to use supine position and did not feel comfortable using other positions:

"Providers are used to supine position, we are taught that way, therefore it is difficult for us to change without being exposed to the procedures of conducting a delivery in non supine positions." (Doctor, interview, coastal district hospital)
"Although the woman has the right to choose the position she likes for delivery, midwives are not conversant with other positions apart from the supine. We were not trained to use these non-supine positions." (Midwife, FGD, referral hospital)

\section{Do providers know what women want?}

We asked what providers thought were women's preferences regarding mobility and different positions for delivery. For mobility, we found some inconsistency between what providers thought women wanted and what women said they would prefer. Most doctors we interviewed, and midwives who participated in focus group discussions, suggested women do not like to walk around during labour, but prefer to rest or lie down:

"Many do not like to walk. For those we have there, the most they can do is to go to the toilet. Walking around! No they don't like that." (Doctor, interview, regional hospital)

"Some primigravidas may agree to be mobile when you tell them but mutigravidas may be resistant." (Midwife, FGD, district hospital)

These findings are incompatible with women's preferences identified during exit interviews, which suggested some women do want to be mobile during labour. Of the 671 women who stayed in bed in the labour ward, $28.3 \%$ wanted to move around while in labour. More than $37 \%$ of women at the district hospital wanted to be mobile; more than $25 \%$ of women at the referral and regional hospitals, and $21 \%$ at coastal district hospital said they wanted to move around during labour (see table 4).

Provider views and women's preferences regarding position for delivery were mostly consistent. The consensus among midwives was that women are used to supine position, they prefer to lie on their backs, and even turn onto their backs out of habit. The following extracts illustrate typical comments from focus group discussions:

"They (women) like it and are used to supine position. They immediately lie on their backs as soon as a contraction starts, thinking that they are ready to give birth." (Midwife, FGD, coastal district hospital)

"I think women like to lie on their backs. What I have observed is that even if you do not tell them anything about position, they turn and lie on their back." (Midwife, FDG, coastal district hospital)

The doctors we interviewed also agreed that women generally prefer to deliver lying on their back in supine position: 
"Women like to lie on their back since generation after generation no other position has been used." (Doctor, interview, regional hospital)

"Women obviously like supine positions since it is used more often. This is the only position they know that is used in health facilities." (Doctor, coastal district hospital)

One doctor described in more detail why this was the case, explaining that women do not have the choice of which position to deliver in:

"A few may not like it (supine position), but they have no choice. Some want to deliver lying on their side or even in upright positions but we tell them to lie on their back." (Doctor, interview, referral hospital)

Provider views were generally comparable to women's preferences identified during exit interviews. As shown in Table 5, the majority of women said they would choose supine position, with very few indicating that they would choose sitting or squatting.

\section{What is required to encourage informed choice for women?}

We asked providers what should be done to ensure more informed choices for women for position during labour and delivery in their hospitals. Both midwives and doctors suggested that women should be encouraged to be mobile, since they are currently unaware of the benefits; typical comments included:

"We really cannot say for sure if women do not like being mobile. Women have not been asked. I am sure if we told them of the benefits and asked them their preferences, their responses would be different." (Midwife, FGD, referral hospital)

"If women get the education and are encouraged, and if something is done about the space in the labour wards, women can move around. This education needs to start during antenatal care and also the people at home should know the importance of mobility. Some women are literally carried by their relatives when coming to hospital, even if labour has not progressed." (Midwife, FGD, referral hospital)

Doctors we interviewed specifically mentioned the need for health workers to encourage women to be mobile:

"Women are not encouraged to walk. Health workers tend to forget to educate women on the benefits of mobility." (Doctor, interview, referral hospital)
"I think women need to be encouraged to be mobile since some of them stay immobile due to the belief that they are supposed to stay in bed when they are in the labour ward." (Doctor, interview, regional hospital)

Both midwives and doctors suggested that they required training on the use of positions other than supine and that this would help them to offer more choice to women for their position during labour and delivery:

"Health care providers, especially midwives and doctors need to be trained. The health care providers can then educate and sensitise women on the use of positions other than supine." (Doctor, interview, coastal district hospital)

"We (midwives) need training on other positions. You must know how to deliver the baby if a woman chooses another position like upright or lateral. This training should take into consideration the actual situation in our labour and delivery wards." (Midwife, FGD, referral hospital)

\section{Discussion}

The study identified a need for provider training to enable more informed choices for women regarding position during labour and delivery. Providers at the four study sites were clearly aware of the benefits of mobility during the first stage of labour and positions other than supine for delivery, but increasing the choice for women is dependent on changing provider opinions about what women prefer, their views about barriers and facilitating factors, and building their skills and confidence through training.

\section{Women's preferences}

The study findings indicate that more women were mobile at home than in the labour ward, but still movement was quite restricted at home before women were admitted to the labour ward. Women's choice to rest with little movement at home might be an important consideration in changing practice. However, as the quantitative results show, $28.3 \%$ of women who laboured in bed in the labour ward actually wanted to be mobile. Qualitative findings from interviews and focus group discussions with labour ward staff imply that providers do not necessarily know women's preferences, and are hesitant in allowing women to be mobile because of concern over their safety and the restrictive ward environment. For women's preferences to be met will require a change in provider attitude as well as training to overcome their fears and concerns. Future research should assess the effects of provider training on informed choice for women, and whether women who are informed about the benefits of mobility and encouraged to be mobile remain in bed or choose to move around when in the labour ward. 
The findings demonstrate consistency between actual practice for delivery position, provider views and women's preferences. Supine position is used routinely at all four study sites, and this also appears to be the choice of women and providers. However, this apparent synergy between women and provider views is misleading. Tanzanian women traditionally favour delivering in upright positions, as indicated by the TBA's we interviewed, but those women who deliver in hospitals are mainly delivered in the supine position. Women's preferences expressed in this study could be influenced by their tendency to accept the suggestions of professionals in health care facilities; this effect of the medicalisation of childbirth is a challenge to the profession. As scientific evidence is beginning to demonstrate the benefit of traditional practices, such as mobility and upright positions for delivery, support for their use in institutional deliveries is growing.

\section{Next steps in changing practice}

Changing habits and established practice is a difficult and complex process. As the qualitative findings in this study reveal, encouraging changes to practice is particularly challenging if health care professionals do not internalise the need for change, if they are afraid of the implications of a change in practice, and if the change requires new skills and training.

Health care providers agreed that women should be encouraged to be mobile during labour, and doctors in particular thought it should be the responsibility of health workers to educate women about the benefits of mobility. However, the main barriers to encouraging mobility appeared to be providers' concern over the safety of women who are mobile, their lack of control and their fear of women delivering outside of the labour ward; others suggested that overcrowding on labour wards made it difficult to allow women to get out of bed. Despite these apparent obstacles to change, one hospital reported encouraging mobility during labour (immediately after baseline data collection); this change in practice can probably be attributed to the efforts of one influential obstetrician (personal communication).

Providers also expressed concern over the safety of using positions other than supine, and particularly their lack of experience and training meant they did not feel comfortable encouraging women to deliver in more upright positions. Doctors and midwives communicated the need for training to acquire the new skills necessary to assist women to deliver in upright or lateral positions. Health provider training, or educational outreach is one possible intervention that can be used to disseminate information on best practice and initiate change in health professionals' practice [24]. However, given the complex individual, social and organisational factors that influence provider practice in this setting, a multifaceted approach that combines several interventions might be more effective [25].

The Better Births Initiative is a health care provider targeted educational outreach package that also uses a local opinion leader to introduce evidence-based standards and encourages labour ward staff to consider the potential benefits and harms of practices they use. The package uses a workshop with interactive materials, including a workbook, reference materials, posters and a self-audit mechanism, to help health professionals understand research evidence, make decisions about best practice, and establish implementation procedures to assure change [26]. An evaluation at government hospitals in South Africa found a positive impact on practice, and the Initiative has since been rolled out to other provinces in South Africa and adapted for use with clinicians in other settings [6]. In the second phase of the Tanzanian study we plan to adapt materials from the Better Births Initiative, and in consultation with key informants at study sites develop a training package for labour ward staff to help them consider helping women to make more informed choices about positions during labour and delivery. The training package will be followed with a post-intervention evaluation, and practice rates and qualitative data compared to baseline findings. The pre-post comparison will be reported in a subsequent paper.

\section{Limitations}

The study was conducted at four hospitals in two regions of Tanzania. Although the hospitals represent different levels of care, the findings cannot be generalised to hospitals in other regions. Exit interviews were conducted at one time point only, and therefore might not adequately reflect average practice rates throughout the year.

In some cases, trained midwives from the study sites (not working in the labour ward) conducted exit interviews with postnatal women; which is a potential source of bias. However, since no midwives at the study sites had previously attended any training on evidence-based standards for obstetric care, it is unlikely that their involvement in baseline data collection affected the validity of the quantitative data. We plan to control for this bias at follow-up by employing student nurses, impartial to the outcomes of the training, to conduct exit interviews.

Data from exit-interviews with women should be interpreted with some caution; all women were interviewed at the health facilities, therefore there is a risk of 'courtesy bias', or women providing what they believe are acceptable responses rather than their own opinions. However, interviewing postpartum women outside the health facility is problematic in the Tanzanian setting, since it is dif- 
ficult to trace women at their home addresses once they leave the hospital, and transportation to rural areas can be difficult.

To avoid losing meaning of concepts through the process of translation, qualitative data analysis was conducted in the language used for data collection (Kiswahili); key themes and concepts were then translated into English for further analysis and interpretation. This process cannot totally preclude loss of meaning, especially as some words and phrases do not have meaningful English equivalents.

\section{Competing interests}

None declared.

\section{Authors' Contributions}

HL, RM and HS devised the study design and objectives. HL and RM were responsible for the conduct of the study. HL and RM analysed and interpreted data. HS provided technical support, contributed to data analysis and interpretation, and drafted the paper. HL and RM helped write the paper, and all authors read and approved the final manuscript.

\section{Acknowledgements}

To the women, midwives and doctors from Dar es Salaam and the Coast region who participated in the study. To Tumaini Nyamhanga for facilitating focus group discussions, Feddy Mwanga for contributing to preliminary analysis of the qualitative data, and Faustin Mayunga for entering data into Epi Info. To the Department for International Development, UK for funding the project.

\section{References}

I. National Bureau of Statistics (Tanzania) and Macro International Inc: Tanzania Reproductive and Child Health Survey 1999 Calverton, Maryland: National Bureau of Statistics and Macro International Inc; 2000.

2. Lugina HI: Women's postpartum concerns and midwives' reflection on postpartum care: studies in Dar Es Salaam, Tanzania. PhD thesis Uppsala University, Sweden; $200 \mathrm{I}$.

3. Lugina $H$, Mlay $R$, Smith $H$, Lavender $T$ : The Africa Midwives Research Network. British Journal of Midwifery 2002, I 0(7):45 I-454.

4. Sackett DL, Rosenberg WMC, Muir Gray JA, Haynes RB, Richardson WS: Evidence based medicine: what it is and what it isn't. $\mathrm{Br}$ Med J 1996, 3 I 2(7023):71-72.

5. A randomised trial to evaluate a programme promoting evidence-based medicine based on the WHO Reproductive Health Library (WHO/HRP ID number 989/6) [http:// www.who.int/reproductive-health/rhl/trials.html]

6. Smith H, Garner P: Better Births Initiative: A Programme for action in low and middle-income countries. In Global Health Council. Making childbirth safer through promoting evidence based care [Technical Report] Washington DC: Global Health Council; 2002.

7. Chalmers I, Lumbiganon P: The Cochrane Collaboration: providing research synthesis to inform health care and research. Sci Asia 2002, Suppl:9-I4.

8. Langer A, Villar J: Promoting evidence based practice in maternal care. Br Med J 2002, 324:928-929.

9. Villar J, Carroli G, Gulmezoglu M: The gap between evidence and practice in maternal healthcare. Int J Gynaecol Obstet 200I, 75:S47-S54.

10. Crowley P: Prophylactic corticosteroids for preterm birth. Cochrane Database Syst. Rev. 2000, CD000065(2):.
II. Duley L, Henderson-Smart D: Magnesium sulphate versus diazepam for eclampsia. Cochrane Database Syst. Rev. 2003, CD000I 27(4):

12. Gülmezoglu AM, Duley L: Use of anticonvulsants in eclampsia and pre-eclampsia: survey of obstetricians in the United Kingdom and Republic of Ireland. $\mathrm{Br}$ Med J I998, 3 I 6(7 I36):975-976.

13. Van Someren V: Changing clinical practice in the light of the evidence: two contrasting stories form perinatology. In Getting research findings into practice Secondth edition. Edited by: Haines A, Donald A. London: BMJ Publishing Group; 2002.

14. Lewis L, Webster J, Carter A, McVeigh C, Devenish-Meares P. Maternal positions and mobility during first stage labour (Protocol for a Cochrane Review). In The Cochrane Library Issue 4 Chichester, UK: John Wiley \& Sons, Ltd; 2003.

15. Gupta JK, Nikodem VC: Women's postion during second stage of labour (Cochrane Review). Cochrane Database Syst. Rev. 2000, CD002006(2):.

16. Midwives Information and Resource Service (MIDIRS) and the NHS centre for Reviews and Dissemination: Positions in labour and delivery. Informed Choice Leaflet number 5 Bristol MIDIRS; 1999.

17. Qian X, Smith H, Zhou L, Liang J, Garner P: Evidence-based obstetrics in four hospitals in China: An observational study to explore clinical practice, women's preferences and provider's views. $B M C$ Pregnancy Childbirth 200 I, I:I.

18. Khalil K, Cherine M, Elnoury A, Sholkamy H, Breebaart M, Hassanein $\mathrm{N}$ : Labour augmentation in an Egyptian teaching hospital. Int J Gynaecol Obstet in press.

19. StatsDirect statistical software [http://www.statsdirect.com]

20. Dean AG, Dean JA, Columbier D, Brendel KA, Smith DC, Burton AH, Dicker AC, Sullivan K, Fagan RF, Arner TG: Epi Info, Version 6: a word processing, database and statistics programme for public health on IBM-compatible microcomputers. Atlanta, Georgia: Centres for Disease Control and Prevention 1995.

21. Ritchie J, Spencer L: Qualitative data analysis for applied policy research. In Analysing qualitative data Edited by: Bryman A, Burgess RG. London: Routledge; 1994.

22. Glaser B, Strauss A: The discovery of grounded theory. New York: Adline Publishing; 1967.

23. Glaser B: Theoretical Sensitivity. California: Sociology Press; 1978.

24. Thomson O'Brien MA, Oxman AD, Davis DA, Haynes RB, Freemantle N, Harvey EL: Educational outreach visits: effects on professional practice and health care outcomes. Cochrane Database Syst Rev 2000, CD000409(2):.

25. Oxman A, Thomson MA, Davis D, Haynes B: No magic bullets: a systematic review of 102 trials of interventions to improve professionals practice. Can Med Assoc J 1995, I 53( I 0): |423-|43|.

26. Better Births Initiative [http://www.liv.ac.uk//stm/ehcap/BBI/bbi mainpage.htm]

\section{Pre-publication history}

The pre-publication history for this paper can be accessed here:

\section{http://www.biomedcentral.com/1471-2393/4/3/prepub}

Publish with Bio Med Central and every scientist can read your work free of charge

"BioMed Central will be the most significant development for disseminating the results of biomedical research in our lifetime. "

Sir Paul Nurse, Cancer Research UK

Your research papers will be:

- available free of charge to the entire biomedical community

- peer reviewed and published immediately upon acceptance

- cited in PubMed and archived on PubMed Central

- yours - you keep the copyright 